manner as to leave a ledge, on which the base of the stone was to rest, and a perpendicular face rising from it, against which as a buttress one side would bear when set up. From the bottom of this hole an inclined plane was cut to the surface, down which the monolith which had already been dressed was slid until its base rested on the ledge.

(2) It was then gradually raised into a vertical position by means first of levers and afterwards of a ropes. The levers would be long trunks of trees, to one end of which a number of ropes were attached (this method is still employed in Japan), so that the weights and pulling force of many men might be exerted on them. The stronger ropes were probably of hide or hair, but others of straw, or of withes of hazel or willow, may have been in use for minor purposes.

(3) As the stone was raised, it was packed up with logs of timber and probably also with blocks of stone placed beneath it.

(4) After its upper end had reached a certain eleva-

\section{GEOLOGY OF THE MOON.}

FOR many years past geologists have turned wistfully to the moon in the hope of gaining from a study of its surface some insight into planetary evolution, and more especially into some of the stages in the history of our own globe. It must be confessed, however, that as yet few satisfactory data have been obtained, either in the facts observed or in the deductions drawn from them. The great majority of those who have studied the subject have formed the opinion that our satellite was once a liquid mass, such as we believe the earth itself to have also been, and that its so-called "craters" represent extensive and prolonged volcanic activity, when the gases and lava of the heated interior escaped to the surface, probably on a scale of magnitude greatly surpassing that on which subterranean energy has ever been manifested in the geological history of our planet. But another explanation has been proposed for these lunar features, according to which, as worked out by Mr. G. K.

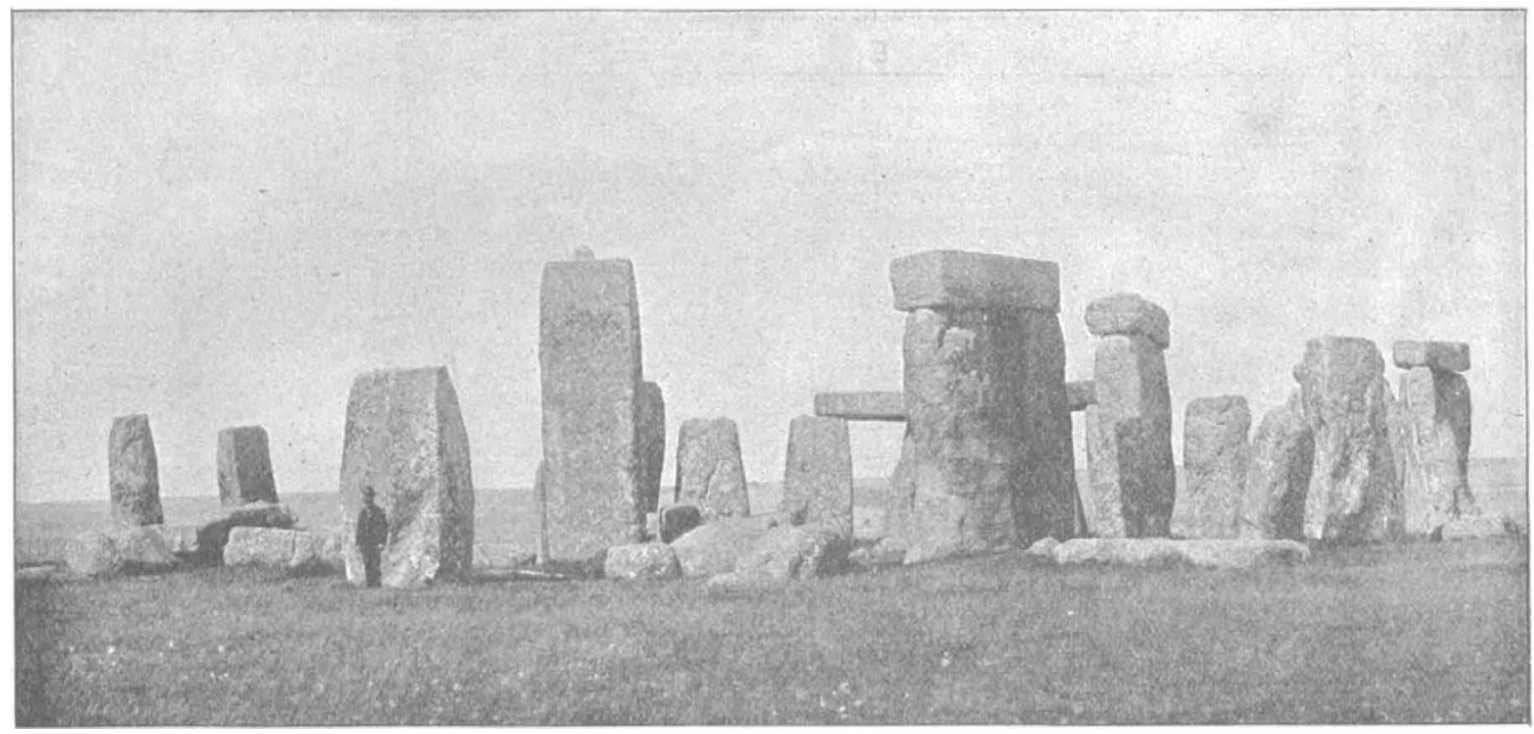

FIG. 7.-The present aspect of the monument with the leaning stone raised.

tion, ropes were attached to it, and it was then hauled by numerous men into a vertical position, so that its back rested against the perpendicular face of the chalk which had been prepared for it. During this part of the operation, struts of timber would probably be placed against its sides to guard against slip.

As regards the raising of the lintels, and imposts, and the placing of them on the tops of the uprights, there would be even less difficulty than in the erection of the uprights themselves.

It could be easily effected by the simple method practised in Japan for placing heavy blocks of stone in position. The stone, when lying on the ground, would be raised a little at one end by means of long wooden levers. A packing of logs would then be placed under the end so raised, the other extremity of the stone would be similarly raised and packed, and the raising and packing at alternate ends would be continued until the block had gradually reached the height of the uprights. It would then be simply pushed forward by levers until it rested upon them.

I shall deal later on with several interesting conclusions to which these investigations lead.

NORMAN LOCKyer.
Gilbert, of the United States Geological Survey, the moon was formed by the aggregation of a ring of meteorites which once encircled the earth, and the " craters," instead of arising from the escape of volcanic energy from within, were produced by the impact of the last meteoric bodies that fell from without. These bodies, arriving with planetary velocity, would be melted or reduced to gas, while a portion of the lunar surface around them would also be liquefied. Mr. Gilbert believes that the lunar topography bears witness to such a meteoritic bombardment rather than to gigantic volcanic explosions.

The latest contribution to the discussion was recently presented to the Academy of Sciences of Paris by MM. Lowy and Puiseux. These eminent astronomers direct attention to the evidence furnished by the latest photographic charts of the "Atlas Lunaire " in regard to the conditions in which a planetary body passes from the liquid to the solid state, and to the stage in this transformation which has been reached respectively by the earth and the moon.

With respect to the evolution of the earth two opposite theories have been propounded. The great body of geologists have maintained that the interior

NO. I 84 I, vOL. 7 I 7 
of the planet is an iricandescent mass which is slowly cooling and consolidating from the surface inward, and is enclosed within a comparatively thin solid crust. Some distinguished physicists, however, have contended that the first formed crust would break up, sink down, and be re-melted; and thus that permanent consolidation would begin at the centre, and would gradually extend outwards, until eventually the whole globe became practically solid, with only here and there large vesicular spaces whence active volcanoes are supplied. The densest and least fusible materials would thus tend to accumulate towards the centre, and the lightest and most fusible towards the outside. The geological belief rests upon a large body of evidence from the structure of the terrestrial crust, which it is difficult or impossible to explain except on the supposition of an internal mass which at least in its outer parts is sufficiently liquid to emerge at the surface as molten lava. The physical argument rests on certain mathematical assumptions the validity of which has been contested. One of these assumptions is that if the interior were liquid, tides would be set up in its mass, and the crust would rise and fall with the passage of the internal tidal wave. Another objection is based on the supposition that huge mountain-chains could not possibly be supported by a thin crust, but would sink down into the interior. More recently the idea has been suggested that the internal core of the earth is gaseous. At the high temperatures and enormous pressures in the interior of the planet, gaseous iron or lava must be more incompressible than steel is at the surface. On the outside of this gaseous mass it is believed that the materials pass into the liquid form or magma which extends as a comparatively thin envelope round the gaseous core, and shades off outward into a solid crust which may not be more than twenty-five or thirty miles in thickness. The most recent earthquake observations have been quoted in support of this view.

Messrs. Lœwy and Puiseux approach the subject impartially from a study of the phenomena presented by the surface of the moon as recorded in a series of photographs. They accept the general belief that our satellite was once a liquid globe, and that traces of its passage from that condition to its present state of consolidation can be clearly recognised. They cannot say whether its temperature increases with depth from the surface, or if there is any variation in density, but they find in their photographs various particulars which, in their opinion, show that the solidification started from the surface.

The differences of level on the surface of the moon are relatively greater and more abrupt than those on the surface of the earth, and they display in many ways the dynamic effects which a liquid when in movement exerts on its solid containing walls, such as the superficial outpourings which have covered two fifths of the visible lunar surface and have turned these tracts into continuous plains, round the margins of which numerous remains of the previous relief have been left. Other effects are seen in the traces of instability in the mountain ranges, the fractures, sharply-defined terraces and marginal fissures so often observable. The neighbourhood of a great sheet of liquid material is required to account for the undulations and horizontal displacements which have affected large tracts of the surface, such as the breaking down of the crest of the Apennines, the separation of the rectangular blocks of the Caucasus, and the formation of the rectilinear valleys of Rheita, the Alps, and Ariadæus.

The most decisive argument in favour of the gradual cooling of the moon from the outside towards the interior appears to be furnished by some facts which are brought out with great clearness by the NO. I $84 \mathrm{I}$, VOL. $7 \mathrm{I} 7$ recent photographs. Thus the two French astronomers have satisfied themselves that after the first establishment of a thin crust the inward retreat of the liquid took place gradually, until the fatal moment arrived when it partly lost connection with the overlying solidified crust, so that an intermediate vacant space was left between them. This temporary interval, being filled with gas at a high pressure, formed a cushion which was sufficiently elastic to prevent any falling-in, but was too limited in extent to affect isostatic compensations, so that the internal tides might be developed without endangering the external figure of the moon. When, for some unknown reason, as happens also on our globe, the lunar eruptive forces assumed special vigour, the crust, yielding to the pressures along its least resisting parts, was overflowed by the liquid interior. Such local subsidences gave rise to the great cirques and various other features in the polar region, where the cooling was most rapid, and where, for easily intelligible reasons, the crust reached a considerably greater thickness. But in the equatorial zone, where the tides and the centrifugal force are most powerful, these violent perturbations led to vast subsidences which now form the lunar "seas." The survival of remains of the earlier topographical relief, still visible along the borders of these tracts, bears witness to the nature of the gigantic changes. Each eruptive movement has marked, by the level bottom of the formations, the height of the level of the subjacent liquid. Five such stages in the subsidence of the molten matter are displayed in the photographs. We can understand that the process would be repeated with diminishing energy until the gradually thickening crust presented too great an obstacle to the eruptive action. Various striking examples are cited by the authors; in particular one where the five platforms are separated from each other by a step-like interval of several thousand metres. Had the consolidation begun at the centre of the moon, it is contended, the result would have been altogether different, for then only the latest level should have been seen, and the eruptive forces would have had neither an opportunity of manifesting themselves nor the means of leaving permanent traces at very different stages.

MM. Lowy and Puiseux examine the argument from the tides in favour of the consolidation of a planet from the centre outwards, and remark that it must be considered as doubtful, because we do not know how far the coefficient of viscosity or internal friction, which has been employed in the calculations, agrees with the reality. They suggest that as the materials in the interior are under enormous pressure they may quite possibly have such viscosity, and yield so slowly to planetary influences, which are continually changing in direction in consequence of the diurnal movement, that no appreciable tidal deformation may result. In the case of the moon it is admitted that the tides in the still liquid mass would for a long time delay the formation of an outer crust, which before its final establishment must have undergone many violent disruptions, when its brokenup sheets were overflowed by the molten matter from within. But in the course of time it has ended by attaining a great thickness in consequence of continual cooling and the contraction of the outer layers.

The argument that on the supposition of a comparatively thin crust the existence of mountainous moon, where the force of gravity is six times less than on the earth. But in the opinion of the two French astronomers the argument need not be seriously considered, either for our planet or for our satellite, inasmuch as it depends on a problematic theory which is entirely based on an inaccurate 
hypothesis of homogeneity. Mountainous excrescences, so far from weakening the general stability, really conduce to it; they are not only held up by the tenacity of the neighbouring parts, but, as Airy suggested, they probably have roots which plunge down into material of greater density and permit them to float.

The authors affirm, in conclusion, that their detailed study of the moon appears to them to confirm geologists in their preference for the theory of a thin crust and to indicate that the transition to solidity, still incomplete for the moon, is far from having reached its end upon the earth. Arch. Geikie.

\section{NOTES.}

WE regret to announce that Prof. G. B. Howes, F.R.S., died on Saturday last, February 4, at fifty-one years of age.

IT is proposed to erect a monument at Laibach, in Austria, to the memory of Vega, author of the well-known table of logarithms, which is now in its eightieth edition.

From the American Mathematical Bulletin for January we learn of the death of Dr. Francesco Chizzoni, professor of geometry at Modena, and of Prof. Achsah M. Ely (Miss Ely), head of the department of mathematics at Vassar College, U.S.A.

ThE Wilde medal of the Manchester Literary and Philosophical Society has been awarded to Prof. C. Lapworth, F.R.S. The medal will be presented on February 28 , when the Wilde lecture of the society will be delivered by Dr. D. H. Scott, F.R.S., on "The Early History of Seedbearing Plants, as recorded in the Carboniferous Flora."

FOR the past year, a station for solar research has been maintained on Mount Wilson, California, by the Yerkes Observatory, with the aid of a grant from the Carnegie Institution of Washington. This station has now been replaced by a new solar observatory which has been established by the Carnegie Institution, and the following staff, formerly of the Yerkes Observatory, has been appointed :Prof. G. E. Hale (director), Prof. G. W. Ritchey, Mr. F. Ellerman, and Mr. W. S. Adams.

Prof. Valdemar Stein, leader of a well known Copenhagen analytical and chemical laboratory, where for a number of years official and private tests and investigations in Denmark have taken place, died on February I, aged 69 years. $\mathrm{He}$ took over in 1863 the laboratory founded by $H$. C. Örsted and altered it to its present shape, making it a valuable public institution. Beside his work there Stein was Government adviser in chemical agriculture, and wrote many scientific articles on chemical and agricultural subjects.

THE Imperial Academy of Sciences, St. Petersburg, at the last annual meeting, awarded the Lomonosoff prize of rool. to Prof. N. A. Menschutkin for his well-known and extensive researches in the domain of theoretical chemistry. The Ivanoff prize was awarded to Prof. P. N. Lebedeff, of Moscow, for his remarkable experimental researches on the pressure of light. At the same meeting, Prof. S. Th. Oldenburg declared, in his yearly review of the work of the academy, that the Polar Committee had given up all hope of the return of Baron Edward Toll, F. G. Seeberg, and their two companions. The party was probably lost during the Arctic night while trying to cross the ice-fields lying between Bennett Island and the New Siberian archipelago. NO. I 84 I, VOL. 7 I]
A NATIONAL exhibition of brewing materials and products will be held in Paris during March, 1906.

AT the meeting of the French Physical Society on January 20, under the presidency of M. d'Arsonval, the following officers were elected:-Vice-president, $M$. Amagat; general secretary, M. Henri Abraham; treasurer, M. de la Touanne. The office of president falls on M. Dufet.

THE Times correspondent at Colombo states that Sir H. A. Blake, Governor of Ceylon, announced at the last meeting of the Asiatic Society that Sinhalese medical books of the sixth century described 67 varieties of mosquitoes and 424 kinds of malarial fever caused by mosquitoes.

At the meeting of the Anthropological Institute to be held on Tuesday next, February 14, Dr. A. C. Haddon, F.R.S., will exhibit a series of kinematograph pictures of native dances from the Torres Straits, taken by him when in New Guinea. Applications for admission should be addressed to the Secretary of the Institute at 3 Hanoversquare, W.

A LARGE and influential international committee has been formed in Heidelberg, under the presidency of His Excellency Dr. A. Freiherr von Dusch, Minister of Education, \&c., of the Grand Duchy of Baden, with the object of honouring the memory of the late Prof. Carl Gegenbaur, who for nearly thirty years was the director of the Anatomical Institute of Heidelberg. The committee has decided upon a life-size bust of Gegenbaur, to be executed in marble by Prof. C. Seffner, Leipzig. The bust will be placed in the vestibule of the Anatomical Institute, probably in the early summer, at a date not yet fixed. The committee invites former pupils of the deceased master, and all those who have benefited from his epoch-making works on human and comparative anatomy, to send monetary contributions, with their addresses and titles, to Prof. M. Fuerbringer, or to Prof. E. Goeppert, both in Heidelberg. Every contributor will receive a picture of the bust, and casts may be obtained, on special application, from Prof. C. Seffner.

AfTer an interval of two years the fifth conference of West Indian agriculturists was held at Port-of-Spain, Trinidad, from January 4 to 13 . It was attended by official, scientific, commercial, and practical representatives from all parts. In his presidential address, Sir Daniel Morris gave an interesting survey of the great economic change which is in progress. Taken in the aggregate, sugar cultivation must still be regarded as the backbone of the colonial industries, but in some of the islands it has already become of comparatively little or no importance. Trinidad is now a cacao-producing island, its exports of this commodity having risen to the value of a million sterling per annum. Grenada's cacao exports are valued at $250,000 l$, and Jamaica's at $80,000 \mathrm{l}$. Cotton growing, too, has been successfully re-established in several islands, and remunerative prices for the raw cotton are being obtained from Lancashire merchants. The exportations of fruit far exceed in value those of the staple industry. The development of the tobacco, rubber, sisal hemp, fishcuring, and other industries also came under review, and Sir Daniel dwelt upon the importance of agricultural shows and on the provision made by his department for teaching elementary science and the principles of agriculture in the various colleges and elementary schools. Numerous papers were read and discussed, Prof. d'Albuquerque, Dr. Watts, Prof. Harrison, and others supplying valuable information relating to sugar; Mr. Hart, Mr. de Gannes, \&c., on cacao; Mr. Bovell, Mr. Sands, \&c., on cotton; and so on. 